\title{
Cervical Cerclage
}

National Cancer Institute

\section{Source}

National Cancer Institute. Cervical Cerclage. NCI Thesaurus. Code C102763.

A surgical procedure performed to prevent a miscarriage by stitching the opening of the cervix closed. 